\title{
The Application of Fuzzy Control in Progress Control of Project
}

\author{
Chao Fan \\ School of Management, Xi'an University of Architecture \&Technology, Xi'an, 710055, China \\ 453147100@qq.com
}

Keywords: progress control, fuzzy control, Artificial Intelligence, MATLAB.

\begin{abstract}
The traditional method of engineering progress control possess the nature of hysteresis and passivity and lacks of accurate models. Because the controlling of people's subjective experience takes a great proportion. This paper combines with the intelligent fuzzy control technology and makes innovations on the existing progress control methods. Based on the Mamdani inference engine, this paper has designed Engineering progress Fuzzy Controller. The application of this controller successfully outputs the control variables of cost control, combined with Matlab, query table of cost fuzzy control has been produced. In this paper, the artificial intelligence technology will be lead into the progress control field and inspires a novel thinking to the research in this area.
\end{abstract}

\section{Introduction}

Currently, there are many uncertainties in project management in China. These factors are very complex, changing and difficult to assess, which makes it difficult or even impossible to establish a complete and accurate mathematical model. Meanwhile, in the traditional progress control methods, people's subjective experience still accounts for a large proportion. The control effect is linked to the skills of the controller. Therefore, the application of fuzzy control technology to error analysis and the use of case-based inference approach combining with the control theory to analyze complex problems are now imperative for progress management.

\section{The Principle of Fuzzy Control System}

\subsection{Traditional progress control}

The so-called progress control refers to the process to supervise, inspect, guide and correct the entire construction process based on the reasonable and economic project progress plan within the defined period [1]

Traditional project progress control refers to, in the project construction process, first determining the control objectives, and then developing and implementing the corresponding control plan based on the control objectives. Meanwhile, in the implementation of the plan, the progress will be monitored, and the actual data in the construction process will be timely collected and fed back, and the planed value and the actual value will be compared to obtain the error. No error indicates that the plan is properly implemented. If an error occurs, the reasons shall be analyzed first, and the controller shall put forward targeted solutions in accordance with the reasons. And the solutions shall be monitored in a real-time manner. [2] If the measures are effective, the next control stage can be entered. If the effect is not obvious, new solutions shall be re-proposed. Such a cycle shall be maintained until the end of the last control period.

\subsection{Progress fuzzy control of project}

Progress fuzzy control is formed through combination of the fuzzy control technology with the traditional progress control technology. [3] Due to its complexity, the exact model of projects is often difficult to determine, which increases the difficulties to implement the traditional theories and methods and even leads to big differences between the results calculated in accordance with the formula and the actual situation. Then under the current known system, the administrators successfully implement management and control over complex projects by virtue of their rich management experience and excellent management capabilities, thereby achieving good 
management results. Therefore, the original idea of intelligent progress control is to simulate the decision-making process of people in the control process through various channels. Fuzzy control is based on fuzzy control theory and belongs to the field of intelligent control research. It is an important and efficient nonlinear control measure. [4]In this paper, progress fuzzy control is defined as the progress control process which uses intelligent means to collect information to achieve the set control objectives and then help the administrators provide intelligent decision-making through information processing and feedback.

\section{Research on Design and Inference of Project Process Fuzzy Controller}

\subsection{Fuzzification of input and output variables}

Fuzzification of input and output variables is generally divided into four basic steps, namely quantization of domain of discourse, fuzzification of exact amount, fuzzy partition and fuzzy expression [5].

Quantization of domain of discourse. By reference to a large number of documents, the paper supposes that the continuous domain of discourse for the progress error $\mathrm{E}$ is $[-10 \%,+10 \%]$, and the continuous domain of discourse for the progress error of Ec is also $[-10 \%,+10 \%]$. The number of variables in the domain of discourse is generally 8 to 16 . After consultation with relevant professionals, the quantization level of input variables $\mathrm{E}$ and $\mathrm{Ec}$ in the paper takes 13 , i.e. $\{-6,-5,-4$, $-3,-2,-1,0,+1,+2,+3,+4,+5,+6\}$. The quantization level of the control quantity $U$ takes 15 , i.e., $\{-7,-6,-5,-4,-3,-2,-1,0,+1,+2,+3,+4,+5,+6,+7\}$.

Fuzzification of exact amount. This paper converts the error E and error change Ec of exact amount within the continuous domain of discourse interval of $[-10 \%,+10 \%]$ into the fuzzy discrete magnitude within the discrete interval of $[-6,+6]$ by formula $1[6]$.

$$
W=I N T \frac{2 n\left(V-\frac{(a+b)}{2}\right)}{b-a}
$$

Wherein, $\mathrm{a}$ and $\mathrm{b}$ are the continuous domain of discourse interval $[\mathrm{a}, \mathrm{b}], \mathrm{n}$ is the discrete interval $[-n,+n], V$ is the exact amount, $\mathrm{W}$ is the fuzzy discrete magnitude obtained, INT represents rounding, and $\mathrm{a}<\mathrm{V}<\mathrm{b}$.

For example: Supposing that $\mathrm{E}$ is $2 \%$ and $\mathrm{Ec}$ is $-0.6 \%$, according to the above formula, it can be obtained that $\mathrm{E}$ in the discrete domain of discourse is corresponding to 1, and $\mathrm{Ec}$ is corresponding to 0 .

Fuzzy Partition. Fuzzy partition is generally divided based on experience. The number of fuzzy subsets is generally calculated by formula 2 :

$$
m=\frac{2 n+1}{p}
$$

Wherein, $\mathrm{n}$ is the discrete domain of discourse interval, $\mathrm{m}$ is the number of subsets, and $\mathrm{p}$ is constant. Supporting that $p=1.5$, the number of the fuzzy subsets of $E, E C$ and $U$ is calculated respectively by formula 2 , as shown below:

$\mathrm{E}=\{\mathrm{NB}, \mathrm{NM}, \mathrm{NS}, \mathrm{Z}, \mathrm{PS}, \mathrm{PM}, \mathrm{PB}\}$

$\mathrm{EC}=\{\mathrm{NB}, \mathrm{NM}, \mathrm{NS}, \mathrm{Z}, \mathrm{PS}, \mathrm{PM}, \mathrm{PB}\}$

$\mathrm{U}=\{\mathrm{NB}, \mathrm{NM}, \mathrm{NS}, \mathrm{Z}, \mathrm{PS}, \mathrm{PM}, \mathrm{PB}\}$

Wherein: $\mathrm{P}$ and $\mathrm{N}$ represent Positive and Negative respectively.

$\mathrm{B}, \mathrm{M}, \mathrm{S}$ and $\mathrm{Z}$ represent Big, Medium, Small and Zero respectively.

Fuzzy Expression. By reference to a large number of data and documents, this paper chooses the triangle membership function to describe fuzzy variables.

The triangular membership function is typically determined by three parameters, namely $\mathrm{a}, \mathrm{b}$ and $\mathrm{c}$ [7]. Namely: 


$$
f(x, a, b, c)=\left\{\begin{array}{cc}
0 & x \leq a \\
\frac{x-a}{b-a} & a \leq x \leq b \\
\frac{c-x}{c-b} & b \leq x \leq c \\
0 & x \geq c
\end{array}\right.
$$

We can use function $\operatorname{trimf}(x,[a b c])$ in MATLAB to express it. Summary The assignment of input variables E and EC and output variable $U$ in this paper is as shown in Table 1, and the membership functions are as shown in Figure 1

Table 1 The valuation table of E, Ec, $U$

\begin{tabular}{cccccccccccccc}
\hline E & -6 & -5 & -4 & -3 & -2 & -1 & 0 & +1 & +2 & +3 & +4 & +5 & +6 \\
\hline PB & 0 & 0 & 0 & 0 & 0 & 0 & 0 & 0 & 0 & 0 & 0.3 & 0.7 & 1 \\
PM & 0 & 0 & 0 & 0 & 0 & 0 & 0 & 0 & 0.3 & 0.7 & 1 & 0.7 & 0.3 \\
PS & 0 & 0 & 0 & 0 & 0 & 0 & 0 & 0.5 & 1 & 0.7 & 0.3 & 0 & 0 \\
Z & 0 & 0 & 0 & 0 & 0 & 0 & 1 & 0 & 0 & 0 & 0 & 0 & 0 \\
NS & 0 & 0 & 0.3 & 0.7 & 1 & 0.5 & 0 & 0 & 0 & 0 & 0 & 0 & 0 \\
NM & 0.3 & 0.7 & 1 & 0.7 & 0.3 & 0 & 0 & 0 & 0 & 0 & 0 & 0 & 0 \\
NB & 1 & 0.7 & 0.3 & 0 & 0 & 0 & 0 & 0 & 0 & 0 & 0 & 0 & 0 \\
\hline
\end{tabular}

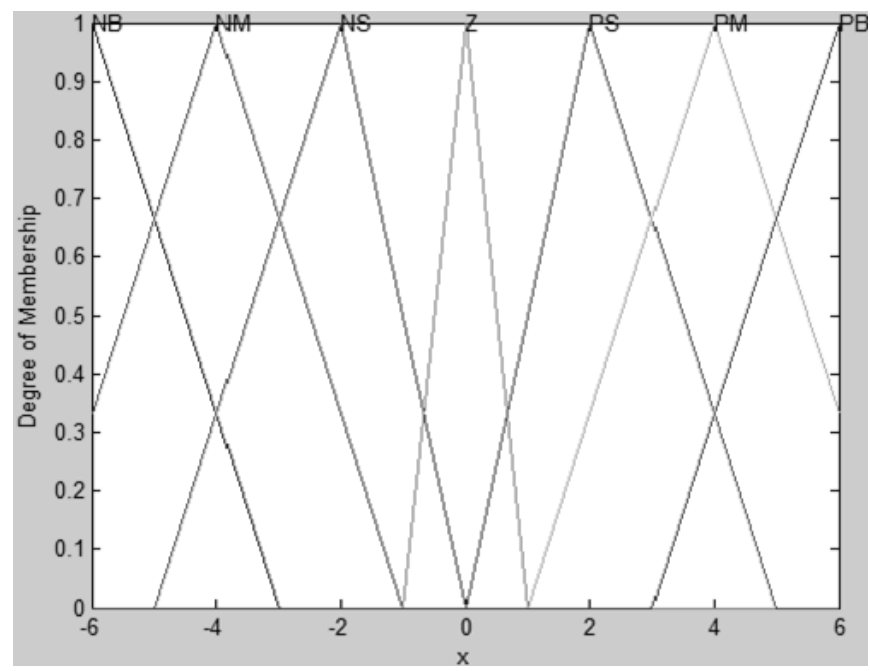

Figure1 The membership function of E, Ec, U

\subsection{Establishment of fuzzy control rules}

Combined with the relevant expert experience, this paper develops a progress fuzzy control table as follows:

It can be seen from the above table that if the progress error is big, a big control quantity $U$ is required to eliminate progress error. If the error is small, a small control quantity $U$ is required to maintain stability. 
Table 2 Rule table of progress fuzzy control

\begin{tabular}{|c|c|c|c|c|c|c|c|}
\hline $\begin{array}{cc} & \mathrm{E} \\
& \mathrm{Ec} \quad \mathrm{U}\end{array}$ & NB & NM & $\mathrm{NS}$ & Z & PS & PM & PB \\
\hline PB & Z & NS & NM & NB & NB & NB & $\mathrm{NB}$ \\
\hline PM & PS & Z & NS & NM & NB & NB & $\mathrm{NB}$ \\
\hline PS & PM & PS & Z & NS & NM & NB & $\mathrm{NB}$ \\
\hline Z & PB & $\mathrm{PM}$ & PS & Z & NS & NM & NB \\
\hline NS & PB & PB & $\mathrm{PM}$ & $\mathrm{PM}$ & Z & NS & NM \\
\hline $\mathrm{NM}$ & $\mathrm{PB}$ & PB & PB & $\mathrm{PB}$ & PS & $\mathrm{Z}$ & NS \\
\hline NB & PB & PB & PB & PB & PM & PS & Z \\
\hline
\end{tabular}

Table 3 Query table of cost fuzzy control

$\mathrm{E}$ $\begin{array}{llllllllllll}-6 & -5 & -4 & -3 & -2 & -1 & 0 & +1 & +2 & +3 & +4 & +5\end{array}$ Ec U

\begin{tabular}{cccccccccccccc}
\hline-6 & +6 & +6 & +6 & +6 & +6 & +5 & +5 & +4 & +3 & +3 & +1 & 0 & 0 \\
-5 & +6 & +5 & +6 & +6 & +6 & +5 & +4 & +3 & +3 & +3 & +1 & 0 & 0 \\
-4 & +6 & +6 & +5 & +5 & +5 & +5 & +4 & +3 & +1 & +1 & 0 & -1 & -1 \\
-3 & +6 & +6 & +5 & +4 & +4 & +4 & +3 & +2 & 0 & 0 & -1 & -3 & -3 \\
-2 & +6 & +6 & +5 & +4 & +4 & +4 & +3 & +3 & 0 & 0 & -1 & -3 & -3 \\
-1 & +5 & +5 & +5 & +4 & +4 & +4 & +2 & 0 & -2 & -2 & -3 & -3 & -4 \\
0 & +5 & +4 & +4 & +3 & +3 & +2 & 0 & -2 & -3 & -3 & -4 & -4 & -5 \\
+1 & +4 & +3 & +3 & +3 & +2 & +2 & 0 & -2 & -4 & -4 & -4 & -5 & -5 \\
+2 & +3 & +3 & +1 & 0 & 0 & -2 & -3 & -4 & -4 & -4 & -5 & -6 & -6 \\
+3 & +3 & +3 & +1 & 0 & 0 & -2 & -3 & -4 & -4 & -4 & -5 & -6 & -6 \\
+4 & +1 & +1 & 0 & -1 & -1 & -3 & -4 & -5 & -5 & -5 & -5 & -6 & -6 \\
+5 & 0 & 0 & -1 & -3 & -3 & -3 & -4 & -5 & -6 & -6 & -6 & -6 & -6 \\
+6 & 0 & 0 & -1 & -3 & -3 & -4 & -5 & -5 & -6 & -6 & -6 & -6 & -6 \\
\hline
\end{tabular}

\subsection{Fuzzy inference and defuzzication of output variables}

Fuzzy inference refers to the interpretation process of specific expression, namely based on fuzzy input set $\mu_{E}(x)$ and $\mu_{E_{C}}(y)$ and input-output relationship contained in the rule base, obtaining the input fuzzy set $\mu_{U}(z)$ of fuzzy controller through fuzzy inference.

So fuzzy relation of various rules Ri can be expressed as:

$$
R_{i}=\left(E_{i} \times E_{C_{j}}\right) \times U_{i j}
$$

Because each fuzzy relation $\mathrm{Ri}$ is associated with a corresponding fuzzy rule, the fuzzy rule matrix of the whole system is:

$$
R=R_{1} \cup R_{2} \cup \ldots \cup R_{49}=\bigcup_{i=1}^{49} R_{i} \quad i=1,2, \ldots, 49
$$

After obtaining the fuzzy relation matrix R, obtain composition rules according to fuzzy reasoning:

$$
U=\left(E \times E_{C}\right) \times R
$$

Namely: 


$$
\mu_{U}(z)=\underset{\substack{x \in X \\ y \in X}}{\vee} \mu_{R_{i}}(x, y, z) \wedge\left[\mu_{E}(x) \wedge \mu_{E_{C}}(y)\right]
$$

The fuzzy output $U$ of project progress fuzzy control can be obtained by this formula. Then defuzzification shall be carried out on fuzzy control quantity U. This paper uses Mamdani inference method to obtain the precise control quantity of the actual output $\mathrm{U}$.

$$
U=\frac{\sum Z_{i} \bullet \mu_{u}\left(Z_{i}\right)}{\sum \mu_{u}\left(Z_{i}\right)}
$$

The precise value of fuzzy output control quantity $U$ can be obtained by formula 8 .

\subsection{Fuzzy Control Query Table}

Because each fuzzy inference needs to consume a lot of resources and time, this paper develops the progress fuzzy control table in accordance with the principle of fuzzy reference. The fuzzy control table will calculate all element combination of input variables, and develop a table based on the calculation results. As the calculated amount is too large, MATLAB is used to develop the table as shown in Table 3

\section{Conclusion}

This paper makes a preliminary exploration of the possibility of application of fuzzy control technology in project progress control. It first determines the progress and control strategies of progress fuzzy control, and then obtains the fuzzy control rules through the fuzzy inference engine, and finally develops the fuzzy control query table and obtains the specific control quantity $\mathrm{U}$, which provides theoretical basis for the specific implementation of subsequent progress control.

\section{References}

[1] Wang Qiang. Initial Exploration of Progress Control Informatization [J]. Construction Management Modernization, 2001 (1): 14-17.

[2] Liu Shuguang, Wei Junmin, Zhu Zhichao. Fuzzy Control Technology [M]. Beijing: China Textile \& Apparel Press, 2001: 158-159.

[3] Yan Yunhua, Chen Min'e, Zheng Bin, Li Bin. Design and Simulation of Fuzzy Controller based on Matlab [J]. Control Engineering of China, 2007, 14 (5): 489.

[4] Li Shiyong. Fuzzy control [M]. Harbin: Harbin Institute of Technology Press, 2011: 235.

[5] Luo Bing, Gan Junying, Zhang Jianmin. Intelligent Control Technology [M]. Beijing: Tsinghua University Press, 2011: 137.

[6] Li Zhiqiang.Design and Simulation of Fuzzy Controller of SBR Sewage Treatment Process [D]. Chongqing: Chongqing University Press, 2008: 23.

[7] Liu Jinkun. Intelligent Control [M].Beijing: Publishing house of Electronics Industry, 2005: 289-290. 